\title{
DESCRIPTION OF CHARACTERISTICS FACTORS AFFECTING THE COMPLICATION OF DIABETES MELLITUS PATIENTS IN ABDUL WAHAB HOSPITAL SJAHRANIE SAMARINDA PERIOD MEI - JUNI 2019
}

\author{
Zakaria Sodiq $^{1}$, Danial ${ }^{2}$, and Yuliana Rahmah Retraningrum ${ }^{3}$ \\ ${ }^{1}$ Medicine Study Program, School of Medicine, Mulawarman University, Indonesia \\ ${ }^{2}$ Laboratory of Medical Anatomy, School of Medicine, Mulawarman University, Indonesia \\ ${ }^{3}$ Laboratory of Medical Internist, School of Medicine, Mulawarman University, Indonesia \\ *E-mail: zakariasapta678@gmail.com
}

\begin{abstract}
Diabetes Mellitus is a chronic disease that most often causes death. Patients with diabetes mellitus who are referred to hospitals have already experienced both macrovascular and microvascular complications. This study aims to determine the risk factors and types of complications that occur in patients with Diabetes Mellitus. This research uses descriptive observational design, with purposive sampling technique. The sample of this study was Diabetes Mellitus patients with complications in Abdul Wahab Sjahranie Hospital Samarinda. There are 52 respondent who met the inclusion and exclusion criteria. Overall data on the characteristics of patients based on age with the most complications are patients aged $<60$ years. As many as 37 people $(71.2 \%)$ and the characteristics of patients based on sex most experienced complications were female sex patients, as many as 36 people $(69.2 \%)$. There is a relationship between student perceptions of the learning environment on campus with an achievement index.
\end{abstract}

Keyword : diabetes mellitus, complication, risk factor

\section{INTRODUCTION}

Prevalence of diabetes meilitus, according to International of Diabeteic Federation Atlas is relatively high and tend to increase ecery year ${ }^{1}$. The number of diabetic patienst in the world reached to 422 million in 2014. The number of cases increased significantly compared to 180 million of cases back in $1980^{2}$. There is an estimated 12.000.000 diabetic patiens in Indonesia ${ }^{3}$. Indonesia is $4^{\text {th }}$ biggest country with the highest increase in diabetic cases growth of $152 \%$ or 8.426.000 cases in the year 2000 to 21.257 .000 cases in $2030^{4}$.

People with obesity have a 4 times higher risk to having diabetes meilitus type 2 compared to people with normal nutritional status ${ }^{5}$. The high number of diabetes Meilitys type 2 prevalence is caused by risk factors that cannot be modified such as sex, age, and genetic factor. Secondly are factors that can be modified such as smoking habit, educational level, job, physical activity, alcohol consumption, and body mass index ${ }^{6}$.

Complications that occur in diabetic patienst cause mortality and non-hyperglycemic morbidity. Diabetes meilitus is often called a deadly disease because it can affect all body organ 
and cause clinical manifestations. Clinical manifestations in diabetic meilitus patients are caused by many things such as individual characteristics e.g. sex, age, educational level, job type, income, the number of family nembers, medical history, and also can be influenced by handling factor such as diet, physical activity, pharmaceutical therapy, and blood sugar monitoring ${ }^{7}$. Complications happen in patients because of patients' ignorance in prevention and treatment of diabetic meilitus. Healthy knowledge is a partof diabetic meilitus management, through knowledge, diabetic meilitus patients can understand their condition and take better care of theirselves. Active participation from diabetic patients results in better self treatment. Diabetes meilitus treatment is not only done by the patient, but the medical team also acts to help patient to form better behavior ${ }^{8}$.

Diabetes meilitus is an incurable condition, however, the blood sugar level can be controlled. Actions to control blood sugar level are physical activity, diabetic diet, therapy management, and following control ${ }^{6}$. There are 4 pillars in diabetic meilitus treatment, which are education, meal planning, sport, and pharmacology intervention ${ }^{1}$. Treatment is done to prevent or minimalize complications caused by diabeteic meilitus ${ }^{9}$.

\section{MATERIAL AND METHOD}

The design of this research is observational descriptive to determine the risk factors and types of complications that occur in patients with Diabetes Mellitus with complications in RSUD Abdul Wahab Sjahranie Samarinda. This study was done at inpatient facility by choosing 5 inpatient wards class 3 which are Angsoka, Seruni, Flamboyan, Dahlia, and Aster. This study was conducted from May - June 2019. The population in this study is diabetic meilitus patient with complication and was put in inpatient ward in RSUD Abdul Wahab Sjahranie Samarinda during the period of May - June 2019 who matched the inclusion criteria set by the researcher. In this study, sampling was done by using purposive consecutive sampling technique, that is when samples were taken based on inclusion and exclusiin criteria during a certain time period set by the researcher, which was done by giving questionnaire to diabetic meilitus patients with complication who were treated in RSUD Abdul Wahab Sjahranie from May - June 2019. Data analysis was done by using Microsoft Word 2016, Microsoft Excel 2016, IBM SPSS 23.

\section{RESULTS AND DISCUSSION}

Based on thisstudy that was conducted from 08 May 2019 - 29 June 2019 on inpatients ward (Angsoka, Flamboyan, Seruni, Dahlia, and Aster) in RSUD Abdul Wahab Sjahranie, researcher only took 64 diabetic meilitus with complication from class 3 ward who matched the 
inclusion and exclusion criteria. From 64 patients, there were 12 patients who were excluded, resulting in only 52 patients were eligible for the study sample. The result of this study is presented using table, graphic, and short naration.

Tabel 1. Complication Type in Diabetic Patients on RSUD Abdul Wahab Sjahranie

\begin{tabular}{lcc}
\hline \multicolumn{1}{c}{ Complication } & $\mathbf{N}$ & $\mathbf{( \% )}$ \\
\hline Ulcus & 28 & 53,8 \\
Gangrene & 11 & 21,2 \\
Renal Failure & 7 & 13,5 \\
Stroke & 4 & 7,7 \\
Heart & 2 & 3,8 \\
\hline Total & 52 & 100 \\
\hline
\end{tabular}

DM patients with macrovascular complication and microvascular compliation, there were 28 patients with ulcus, 11 patients with gangrene, 7 patients with renal failure, 4 patiens with storkem and 2 patients with coronary heart disease. This study corelates to study done by Adabiah (2014), who said that there wew 112 patients with ulcus in RSUD dr, Moeradi ${ }^{10}$. Different from a study conducted by Hasneli, who said that the most common complication found in DM patients were pedis gangrene (42 people), followed by 21 patients with strokem and 13 patients with retinopathy ${ }^{11}$.

Blood glucose level in diabetic meilitus patients, if not controlled properly results in complications that can worsen the prognosis such as ulcus, blindness, renal failure, stroke, gangrene, etc ${ }^{12}$. Ulcus is one of the most feared complications because of reduced blood supply to tissue which results in tissue's death ${ }^{13}$. Ulcus is the most common complication in diabetic meilitus, and gives the characteristic of unhelaed wound, blackish-red and gives a rotten smell ${ }^{14}$.

Tabel 2 Characteristics of Diabetic Meilitus Patients with Complication in RSUD Abdul Wahab Sjahranie

\begin{tabular}{lcc} 
Characteristic & N & $(\boldsymbol{\%})$ \\
\hline Age: & & \\
a. $<60$ year old & 37 & 71,2 \\
b. $>60$ year old & 15 & 28,8 \\
\hline
\end{tabular}




\begin{tabular}{lrc}
\hline Gender : & 16 & 30,8 \\
a. Male & 36 & 69,2 \\
b. Female & & \\
\hline Job status : & 45 & 86,7 \\
a. Employed & 7 & 13,3 \\
b. Unemployed & & \\
\hline Educational Status : & 17 & 32,7 \\
a. > Graduated High School & 35 & 67,3 \\
b. < Didn't Graduate & & \\
\hline Monthly income : & 50 & 96,2 \\
a. < Rp. 3.000.00 & 2 & 3,8 \\
b. > Rp. 3.000.000 & & \\
\hline Knowledge level : & 18 & 34,6 \\
a. Good & 34 & 65,4 \\
b. Enough & 13 & 25,1 \\
\hline Medication Compliance : & 39 & 74,9 \\
a. Complied & & \\
b. Didn't Comply & 50 & 96,2 \\
\hline Time : & 2 & 3,8 \\
a. < 10 years & & \\
b. > 10 years & 10 & 19,2 \\
\hline Self Monitoring Blood Glucose : & 42 & 80,8 \\
a. Good & & \\
b. Enough &
\end{tabular}

Based on the results of the study, the age of patients with diabetes mellitus with complications with age $<60$ years was 37 patients, while age $>60$ years were 15 patients. This is in line with research conducted by Yuhelma, Hasneli and Nauli who examined the identification and analysis of macrovascular and microvascular complications in patients with diabetes mellitus which found that the age of respondents was in the mid 45-60 years ${ }^{11}$. Likewise with the research of Isworo, Mulyati, and Adnan that most DM respondents with complications are in the middle age range $46-59$ years $^{15}$.

Based on the sex-gender of DM patients with complications is the most in women as many as 36 patients, while men as many as 16 patients. These research results arein line with the research conducted by Muhlisin, and Rahmadiliani which states that the sex-gender of people with DM and often experienced the most complications are women ${ }^{16}$. Also in line with the research of Rantung, Yetti, \&Herawati that type 2 DM has more complications in women ${ }^{17}$. 
Based on occupation, DM patients with many complications occured in patients who have job that is as many as 45 patients, while patients who do not work as many as 7 patients. This is contrary to YuniGultom that conducted research on the characteristics of DM patients who have chronic complications, stated that patients who have more complications have more work than do not work ${ }^{18}$. In addition, research from Zainuddin, Utoma, \& Herlina, also reported that some complications in patients with type 2 diabetes were patients with permanent work ${ }^{19}$.

Based on education, DM patients with more complications occured in patients who did not complete secondary education, as many as 36 patients while patients who graduated high school were 16 patients. This is in line with research conducted by Dian Lukman which shows that the majority of respondents' education is low, with a percentage of $80 \%$ consisting of elementary school (SD), junior high school (SMP), while high school (SMA) graduates by $20 \%{ }^{20}$. Also research conducted by Mongonsidi (2014) stated that the proportion of DM patients who experienced complications are mostly in people with low education ${ }^{21}$.

Based on income level, DM patients with complications that taken from the income of most patients experienced complications with low income below the UMR <Rp. 3,000,000, as many as 50 patients, while patients with income>Rp. 3,000,000 were 2 patients. This is in line with the research conducted by Adnyana et al on the characteristics of prevention of complications in patients with diabetes mellitus stated that respondents with diabetes mellitus patients who experience complications are below the UMR of $80 \%^{22}$. In addition, research conducted by Kiadaliri, Najafi, \& Sani, also stated that a group of DM patients who are susceptible to complications in a group of patients with less income level ${ }^{23}$

Based on the level of knowledge, the results obtained are more DM patients who experienced complications with poor level of knowledge as many as 36 patients, compared with good knowledge as many as 16 patients. This study is in line with research conducted by Riyambodo, \& Purwanti stated that the occurrence of various kinds of microvascular and macrovascular complications in DM patients occured mostly in patients with poor level of knowledge ${ }^{24}$.

Based on the level of medication adherence, the results showed that the incidence of complications experienced by DM patients are more common in patients with poor treatment compliance by 38 patients, compared with patients that have good medical adherence as many as 
14 patients. This is in line with research conducted by Kautzky-Willer et al stated that the characteristics of the level of medication adherence in DM patients are still very low, because there are still many patients who do not understand the importance of treatment in DM patients ${ }^{25}$.

Based on the duration suffering diabetes mellitus, the resultsof DM patients who experienced complications with a duration of $<10$ years by 50 patients, while with a duration of $>$ 10 years as many as 2 patients. This is in line with Dahlan's study which showed respondents with DM who developed complications, mostly $<10$ years ${ }^{26}$. In addition, research conducted by Yusra stated that the average respondent of patients with DM has experienced complications with a duration of 1-5 years from the start of being diagnosed with diabetes ${ }^{27}$. The research by Adikusuma also showed that the majority of respondents with a duration of $>5$ years have experienced worsening conditions ${ }^{28}$.

Based on self monitoring, it was found that DM patients who experienced complications with poor self-monitoring were 42 patients, while patients with good self monitoring were only 10 patients. Research conducted by Adam showed that some respondents with DM sufferedfrom complications withpoor $\mathrm{SMBG}^{29}$. However, it is inversely proportional to research by Puspitasari that stated respondents who experienced complications are mostly with good $\mathrm{SMBG}^{30}$. besides Dewi's research also showed that getting the results of respondents who have a good SMBG even though DM patients have complications ${ }^{31}$.

\section{CONCLUSION}

Based on the results of the study, it can be concluded:

1) The most common complication in DM patients iarecomplication of diabetic ulcer type. As many as 28 people (53.8\%), due to hyperglycemia that is not controlled well, other complications can also occur.

2) The characteristics of patients based on age that has the most complications are patients aged $<60$ years. As many as 37 people (71.2\%), at the age of patients complications have occurred before entering the elderly, with this that DM disease with complications can occur in adult patients. 
3) Characteristics of patients based on sex with the most complications are femalepatients. As many as 36 people (69.2\%), the most frequent female with less physical activity, not only women but men have the same risk of the possibility of complications.

4) Characteristics of patients based on occupation, the most complications are patients who work. As many as 45 people (86.7\%), the work of patients did not rule out the possibility of work that only stayed indoors and the influence of excessive food intake can occur from DM to complications.

5) Characteristics of patients based on their most recent education experiencing the most complications are patients that not completed high school. As many as 35 people $(67.3 \%)$, in the last education determine the relationship with the level of knowledge of patients with DM experienced to do self-care but a good level of knowledge is not a determining factor for delaying complications.

6) Characteristics of patients based on monthly income that have the most complications are patients earning less that Rp. 3,000,000. As many as 50 people (96.2\%), at low income, that indicated the existence of inappropriate food intake factors and inhibitors of DM treatment costs, but there were also people with high incomes, but their food intake was not appropriate.

7) Characteristics of patients based on the level of knowledge, patients that experiencing complications are patients with poor knowledge. As many as 34 people (65.4\%), the level of knowledge is expected to direct patients that more actively and regularly in treatment and care in order to preventing complications

8) Characteristics of patients based on adherence to medical treatment with the most complications are patients who do not comply with treatment. As many as 39 people (74.9\%), on medication adherence, with the aim of preventing complications but the improper drug actually causes hypoglycemia.

9) Characteristics of patients based on duration of suffering from diabetes, patientsthat experiencing complications are <10 years. As many as 50 people $(96.2 \%)$, long duration of suffering did not guarantee the limit of complications even with the wrong lifestyle factors can also accelerate the emergence of complications. 
10) Characteristics of patients based on self-monitoring of blood glucose (SMBG) having the most complications are those with poor SMBG. As many as 42 people (80.8\%), SMBG aims to improvedthe quality of life of DM patients who experienced complications.

\section{REFERENCES}

1. IDF. Diabetes Atlas Sixth Edition: International Diabetes Federation; (2015).

2. World Health Organization. Global Report on Diabetes. Geneva: World Health Organization. (2016).

3. Basic Health Research (Riskesdas). Ministry of Health's Research and Development Agency of the Republic of Indonesia in 2013. (2013). Accessed: 19 October 2014

4. World Health Organization .Diagnostic criteria and classification of hyperglycaemia first detected in pregnancy (2015).

5. World Health Organization. Diagnostic criteria and classification of Diabetes. Geneva: World Health Organization (2017).

6. Klaus-Dieter Kohnert, Peter Heinke, Lutz Vogt, Eckhard Salzsieder. Utility of different glycemic control metrics for optimizing management of diabetes. World J Diabetes ; 6(1): 17-29 ISSN 1948-9358 (online) (2015).

7. Permana, H.,. Chronic Complications and Concomitant Diseases in Diabetes. Scientific articles. Scientific journals. Division of Endocrinology and Metabolism Department of Internal Medicine Padjadjaran University Medical School. Hasan Sadikin Hospital. Bandung (2013).

8. Basri, H. Wulandini, P. \& Saputra, R. The Relationship of Diabetes Mellitus Patients to the Occurrence of Diabetes Mellitus Injuries in the Disease Room in RSUD. Arifin Achmad New week. Journal of Health. DIII Nursing of Abdurrab University (2016).

9. RI Ministry of Health. Indonesia Health Profile. Jakarta: Ministry of Health Republic of Indonesia; (2014).

10. Adabiah .Relationship between Family Support and Self-Esteem in Diabetic Ulcer Patients in the Inpatient Room of Internal Medicine Section. DR. M. Djamil Padang (2014).,

11. Yuhelma, Yesi Hasneli, Fathra Annis Nauli. Identification and Analysis of Macrovascular and Microvascular Complications in Diabetes Mellitus Patients. Bibliogaphy, (2013).

12. Lestari D. T., Factors Affecting Insulin Initiation in Type 2 Diabetes Mellitus Patients in Kudus District Regional Hospital. Thesis. Masters in Nursing. University of Indonesia. (2013).

13. Billous R, \& Donelly R. Diabetes Handbook, Issue 4. Jakarta: Bumi Medika (2015). 
14. Marewa, L. W. Diabetes (Diabetes mellitus) in South Sulawesi. Jakarta: Indonesian Torch Foundation (2015).

15. Adnan, M., Mulyati T, Isworo, TJ,. Relationship of Body Mass Index (BMI) With Blood Sugar Levels of Patients with Diabetes Mellitus (DM) Type 2 Outpatient in Tugurejo Hospital Semarang. Journal of Nutrition, Muhammadiyah University, Semarang. (2013).

16. Muhlisin, Abi Rahmadiliani,. Family Nursing Care. Yogyakarta: Gosyen Publishing (2008).

17. Rantung J, Yetti k, Herawati T. Relationship Between Self Care and Quality of Life for Diabetes Mellitus Patients. Scholastic Journal of Nursing. 2015.

18. Gultom, Yuni Thiodora (2012). Level of Diabetes Mellitus Patient Knowledge About Diabetes Mellitus Management at Gatot Subroto Army Hospital Jakarta.

19. Zainuddin, Utomo, W, \& Herlina. The Relationship between Stress and the Quality of Life of Type 2 Diabetes Mellitus Patients. Journal of Medicine UNRI 2 (2015).

20. Dahlan, S.M. Sample Size and Method of Taking Samples. Jakarta: Salemba Medika (2013).

21. Mongonsidi. G. Relationship between socioeconomic status and the incidence of type 2 diabetes mellitus in the internal polyclinic Prof. Dr. R. D Kandou Manado (2014).

22. Adnyana, I. K., Andrajati, R., Setiadi, A. P., Sigit, J. I., Sukandar, E. Y. National Institutes of Health Publication. ISO Pharmacotherapy. PT. ISFI Publishing: Jakarta (2014).

23. Kiadaliri, A. Najafi, B. \& Mirmalek-Sani, M, .Quality of Life in people with diabetes; Journal of diabetes \& Metabolic Disorder (2013).

24. Purwanti, O. S. Riyambodo. Analysis of Risk Factors for Foot Ulcers in Patients with Diabetes Mellitus in RSUD DR. Moewardi Surakarta (2017).

25. Kautzky-Willer, A, Harraiter, J, \& Pacini, G. Sex and gender differences in risk, Pathophysiologi and complication of type 2 diabetes mellitus. Endocrine riviews. (2016).

26. Rokhman, S. A. Progressive Muscle Relaxation Therapy Improves the Quality of Life of Type 2 Diabetes Mellitus Patients (2015).

27. Yusra, A. Relationship between Family Support and Quality of Life of Type 2 Diabetes Mellitus Patients in Internal Medicine Polyclinic at Fatmawati General Hospital Jakarta. Thesis. Faculty of Nursing, University of Indonesia (2011).

28. Adikusuma, W. Measurement of the Quality of Life of Type 2 Diabetes Mellitus Patients Getting Oral Antidiabetic at PKU Muhammadiyah Hospital Bantul. Ahmad Dahlan University (2016).

29. Adam, J.M.F . Dyslipidemia. Internal Medicine Teaching Book Volume 3. Jakarta. Department of Internal Medicine Faculty of Medicine, University of Indonesia (2013).

30. Puspitasari, A. Food Consumption Performance, Health Status, Depression Level and Nutritional Status of the Elderly (2014). 
31. Dewi, R. K. . Diabetes Is Not To Be Feared, \& Prevent and Treat Diabetes mellitus. Jakarta: Agromedia Pusaka (2016). 